\title{
SOME OBSERVATIONS ON THE SEROLOGICAL TYPING OF STAPHYLOCOCCUS PYOGENES
}

\author{
BY \\ J. BRODIE \\ From the Department of Bacteriology, Queen's College, University of St. Andrews
}

(RECEIVED FOR PUBLICATION JUNE 21, 1956)

In the past 20 years the serological typing of Staphylococcus pyogenes has advanced from precipitinogen analysis (Julianelle and Wieghard, 1935; Cowan, 1938) to slide agglutination (Cowan, 1939). A year later six further types were added to Cowan's types I, II, and III by Christie and Keogh (1940), and more recently Hobbs (1948) brought the total to 13 . These 13 types are now referred to as the international types.

The most recent classification is based on an analysis of the heat-labile, heat-stable, and blocked antigens (Oeding, 1952, 1953, 1954). Here the antigens are designated alphabetically $a$ to $k$. In the practical application of this classification $d$ and $g$ are not employed, $d$ being common to all strains examined and $g$ too weak an antigen to be easily identified. Strains are grouped according to their antigenic formulae in the live state and subtyped on the basis of the antigens revealed or persisting after autoclaving at $120^{\circ} \mathrm{C}$. for two and a half hours.

Whereas Oeding used strains isolated mainly from cases of human mastitis, this study employed the international types both for preparation of antisera and for absorption procedures. It was expected that, by following the procedures indicated by Oeding and accepting as the base line his formulae for the international types, factor sera like his would be obtained. Certain modifications of procedures were adopted, and, although they appeared to be slight and unlikely to influence the end-result, the resultant sera did not show the expected close correlation. Nevertheless, when applied to field strains, astonishingly consistent results were obtained (Brodie, Jamieson, and Sommerville, 1955; Brodie, Kerr, and Sommerville, 1956; Brodie, Sommerville, and Wilson, 1956).

The details of the procedures used are set forth below.

\section{Methods}

Strains Used.-The 13 international types were obtained from the National Collection of Type Cultures. These were examined on receipt and, before being used to prepare antisera, each had to be (a) haemolytic on horse blood agar, (b) an active fermenter of mannitol, (c) positive for coagulase by tube test (Mackie and McCartney, 1953), and (d) able to grow readily on heart extract agar containing $8 \% \mathrm{NaCl}$.

Some of the types did not at first satisfy all four requirements, being especially reluctant to grow well on the $8 \% \mathrm{NaCl}$ medium. The ability to grow readily on the $8 \% \mathrm{NaCl}$ medium is shown by pathogenic staphylococci in purulent exudates and it was felt that the international types should also show this characteristic before being accepted as ready for use as antigens.

Antisera were made with all the international types.

Suspensions for Immunization.-The strains were grown for $24 \mathrm{hr}$. on the $8 \% \mathrm{NaCl}$ agar, scraped off, suspended in $0.1 \%$ formol saline, and standardized to $2,000 \mathrm{~m}$. per ml. by Brown's scale. In this the procedure differed from that of Oeding, who used formolinized suspensions of his strains grown on nutrient agar without excess of sodium chloride.

Preparation of Sera.-Adult rabbits were given intravenous injections of $0.1 \mathrm{ml} ., 0.2 \mathrm{ml}$., $0.4 \mathrm{ml}$., and $0.8 \mathrm{ml}$. of the formolinized suspensions at three-to-fourday intervals, continuing with $0.8 \mathrm{ml}$. until satisfactory titres were obtained. The rabbits were then bled out under anaesthesia and the sera separated. Carbolic acid was added to give a final concentration of $0.5 \%$.

Tube Agglutinations.-Full-scale tube agglutinations were done using live, formolinized and autoclaved suspensions. These were incubated for four hours at $37^{\circ} \mathrm{C}$. and read after sitting overnight at room temperature. Saline and pooled normal rabbit serum controls were run simultaneously.

Precipitin Tests.-Extracts of the international types were made by the formamide method of Fuller (1938). Ring tests were done with all strains against all 13 antisera.

Absorptions.-Oeding (1953) absorbed his antisera with formolinized strains. In this instance, absorptions carried out with live and formolinized strains completely exhausted all antibodies. It seemed unnecessary, therefore, to formolinize and all absorptions were done with the live organisms. 
When, however, the absorption was done with the autoclaved homologous strain, rather unexpected results were obtained and will be discussed later.

The antiserum to be absorbed was diluted 1:10 with physiological saline and the live heterologue added in portions. After $30 \mathrm{~min}$. at $37^{\circ} \mathrm{C}$. the absorbing strain was removed by centrifugation and another portion added. This was repeated until the antiserum, by slide test, failed to agglutinate the heterologue even after 10 min. rocking but still gave distinct and rapid agglutination with its homologue.

The antigenic formulae, ascribed to the international types by Oeding, did not allow of a $b$ antiserum being prepared, but since all of Oeding's types in his scheme of classification contained antigen $b$, it was decided to proceed without it.

The antisera and absorbing strains are given in Table I.

TABLE I

ABSORBING HETEROLOGUES AND EXPECTED FACTOR SERA OF ANTISERA

\begin{tabular}{|c|c|c|c|c|}
\hline \multicolumn{2}{|c|}{ Antiserum } & \multicolumn{2}{|c|}{ Absorbing Strain(s) $\rightarrow$} & \multirow{2}{*}{$\begin{array}{l}\text { Factor } \\
\text { Serum }\end{array}$} \\
\hline $\begin{array}{c}\text { International } \\
\text { Type }\end{array}$ & $\begin{array}{l}\text { Oeding } \\
\text { Formula }\end{array}$ & $\underset{\text { Type }}{\text { International }}$ & $\begin{array}{l}\text { Oeding } \\
\text { Formula }\end{array}$ & \\
\hline $\begin{array}{r}10 \\
3 \\
1\end{array}$ & \multirow{4}{*}{$\begin{array}{c}a b / a b i \\
a b c / a b c h i \\
a b e / i \\
b c f / c i \\
a b h / h i \\
a b e / i \\
a b e h k / a b h i\end{array}$} & \multirow{4}{*}{ 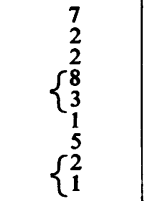 } & \multirow{4}{*}{$\begin{array}{c}\text { bcf/ci } \\
\text { abh/hi } \\
\text { abh/hi } \\
(a) b c / c i \\
a b c / a b c h i \\
a b e / i \\
a b e f / k \\
\text { abh/hi } \\
\text { abe/i }\end{array}$} & $\begin{array}{l}a \\
c \\
e\end{array}$ \\
\hline 7 & & & & $f$ \\
\hline $\begin{array}{l}2 \\
1\end{array}$ & & & & $\begin{array}{l}h \\
\boldsymbol{i}\end{array}$ \\
\hline 4 & & & & $\boldsymbol{k}$ \\
\hline
\end{tabular}

Slide Agglutinations.-Each strain tested was grown for $24 \mathrm{hr}$. at $37^{\circ} \mathrm{C}$. on half of a 3 in. nutrient agar plate, scraped off and suspended evenly in $0.5 \mathrm{ml}$. of physiological saline by whisking with a wire loop.

Every suspension was tested for stability by mixing a small drop with approximately an equal volume of physiological saline and another drop with a 1:10 dilution in saline of pooled normal rabbit serum. If agglutination occurred with one or both, the suspension was recorded as being autoagglutinable. Stable live suspensions were agglutinated drop for drop with the absorbed sera and the results recorded. All suspensions, whether stable or unstable, were now autoclaved at $120^{\circ} \mathrm{C}$. for two and a half hours. Stability tests were repeated, and stable suspensions now tested with the absorbed sera.

For slide tests with live suspensions, the absorbed sera were further diluted 1:10, giving a final dilution of $1: 100$. The autoclaved suspensions would not react with the 1:100 dilution and for them the absorbed antisera were used without further dilution, i.e., at $1: 10$. Only clear-cut agglutinations were accepted; doubtful results were regarded as negative.

A staphylococcus agglutinating with, for example, $a$ and $c$ absorbed sera in the live state and $h$ only when autoclaved was ascribed the formula $a c / h$. This followed the practice of Oeding.

\section{Results}

Tube Agglutinations with Unabsorbed Sera.-So marked were the cross-agglutinations amongst the types that it was obvious that unabsorbed sera were useless for inter-type differentiation. This conforms with the findings of the previous workers (Cowan, 1939; Christie and Keogh, 1940; Hobbs, 1948; Oeding, 1952).

Agglutinations with formolinized suspensions were finely granular and difficult to read.

The control tube agglutination tests showed that all the suspensions were stable in physiological saline but varied in degree of agglutinability over the range of dilutions of pooled normal rabbit serum. This agglutination in the tube with normal rabbit serum is fortunately not reflected to any great extent when using the slide agglutination technique and is adequately covered by the $1: 10$ pooled normal rabbit serum control employed to test stability of suspensions for slide tests.

Precipitin Ring Tests.-These tests were set up and read after one hour at room temperature. The results are given in Table II.

TABLE II

PRECIPITINOGEN ANALYSIS

\begin{tabular}{c|l}
\hline International Type & \multicolumn{1}{|c}{ Positive with Antiserum } \\
\cline { 2 - 2 } 1 & $1,2,3,4,5,7,9,10,11,12,13$ \\
2 & All \\
4 & $4 "$ \\
5 & $1,7,10,13$ \\
6 & None \\
7 & 13 \\
8 & None \\
9 & $1,4,5,7,8,9,10,11,12,13$ \\
10 & $5,8,11,12,13$ \\
12 & $4,5,9,10,11,12,13$ \\
13 & $4,5,9,10,11,12,13$ \\
& \\
\end{tabular}

Here again precipitinogen analysis did not allow of complete differentiation of types. Moreover, it is a procedure wasteful of antisera and timeconsuming in execution. Although cumbersome, it might be useful for strains giving doubtful results.

Slide Agglutination with Absorbed Sera.-Employing the absorbed antisera prepared and diluted as above, the international types were examined. The results are set forth in Table III, which compares the Oeding formulae with the present formulae.

From Table III it is evident that the correlation between the Oeding formulae and those at present presented is not what might have been expected. Admittedly it is confusing to retain the same method of identification of the antigens, but it is perhaps better to do so meantime until a better understanding of this whole complex problem is reached. 
TABLE III

COMPARISON OF OEDING AND PRESENT FORMULAE FOR THE INTERNATIONAL TYPES

\begin{tabular}{|c|c|c|}
\hline $\begin{array}{c}\text { International } \\
\text { Type }\end{array}$ & $\begin{array}{l}\text { Oeding } \\
\text { Formulae }\end{array}$ & $\begin{array}{c}\text { Present } \\
\text { Formulae }\end{array}$ \\
\hline $\begin{array}{r}1 \\
2 \\
3 \\
4 \\
5 \\
6 \\
7 \\
8 \\
9 \\
10 \\
11 \\
12 \\
13\end{array}$ & $\begin{array}{c}a b e i \\
a b h / h i \\
a b c \mid a b c h i \\
a b e h k a b h i \\
a b e f k \\
-(h ?) \\
b c f c i \\
(a ?) b c c i \\
a b c f k i \\
a b a b i \\
\text { autoagglutinable } \\
a b c e c(?) \\
(a ?) b c c \\
(a) b c c i\end{array}$ & $\begin{array}{c}a c e i- \\
-h \\
a c- \\
a c- \\
a- \\
a- \\
a c e h \\
a c h \\
\text { auto } h \\
a c- \\
a c e-\end{array}$ \\
\hline
\end{tabular}

auto $h$ represents autoagglutination in the live state, but $h$ after autoclaving.

- - represents no agglutination either in the live or autoclaved state.

Absorption with Autoclaved Homologous Type.Whereas absorption of an antiserum with its homologous strain in the live or formolinized condition completely exhausted the antiserum, absorption with the autoclaved homologue produced an unexpected enhancement of the agglutination with the formolinized suspension of the strain.

The antiserum made with international type 2 was absorbed with the autoclaved type 2 . The antiserum now agglutinated the formolinized homologue in a very marked and easy-to-read fashion, giving coarse granular agglutination in place of the very fine agglutination obtained with the antiserum before absorption. This enhancement of agglutination was not confined to the homologue but applied also to formolinized suspensions of types 4,5 , and 11 .

It would appear that the removal of the antibodies to the heat-stable antigens removed also a "blocking of agglutination" effect for certain other antigens.

\section{Discussion}

Although the formulae obtained in this investigation did not tally with those of Oeding, nevertheless the absorbed antisera, when applied to field strains, gave astonishingly consistent results. When field strains were examined on the basis of combined serological typing with antibiotic resistance patterns, the ubiquity of certain types of staphylococci in the hospital environment in this area became evident, the nasal and faecal carrier rates could be more adequately defined, and hospital cross-infection with staphylococci more easily investigated (Brodie et al., 1955, 1956a and b).

Koch (1942) showed that Staphylococcus aureus could grow in nutrient media containing up to $10 \%$ sodium chloride; in such media $E$. coli and Proteus spp. are inhibited when the concentration of salt rises above $7 \%$. Hofmeister (1888a and b) showed that, when proteins were "salted out" of colloidal suspension, this precipitation depended on the nature of both the anion and the cation of the salt used. Furthermore, these ions could be arranged in definite series relative to their precipitating powers and to their effects on other physical properties of proteins. In bile salt media, the addition of electrolytes produced, according to the amounts added and their relative positions in the Hofmeister series, a differentiation between " $S$ " and " $R$ ", variants of Salmonella and Shigella (Brodie, 1942). A point was reached in the amount of added electrolyte when the " $R$ " variants were suppressed but the " $S$ " variants grew unimpeded. The employment of one of these media, which suppressed the " $R$ " variants, allowed of a precipitinogen analysis of certain of the Shigella group yielding clear-cut results with a minimum of cross-reactions (Brodie and Green, 1951).

It may not be strictly accurate to compare, on the basis of " $S$ " and " $R$ " variants, the action of high electrolyte content media on Salmonella and Shigella with a similar medium without bile for the Staphylococcus. Nevertheless, it is possible that the nutrient agar with its $8 \%$ sodium chloride, on which the international types were required to grow before being used as antigens, exercisad some peculiar selectivity on the strains-a selectivity which was reflected in the antigenic formulae obtained.

Extensive investıgations are at present being pursued in association with my colleagues in an attempt to throw some light on the peculiarities of the antigenic make-up of the Staphylococcus and what bearing this may have upon phage typing. As this work proceeds, the findings will be reported.

\section{Summary}

The international types of Staphylococcus pyogenes have been investigated and formulae for their major antigens suggested. According to the practice of Oeding (1952), the formula of the live organism is combined with that of the autoclaved. International types $1,2,8,9$, and 12 were found in the present investigation to have the formulae $a c e i /-,-/ h, a c e / h$, and ace/- respectively. Types 3, 4 , and 12 share the formula $a c /-$, while types 5 and 6 share $a /-$. Types 7 and 10 do not yield a formula with the antisera so diluted at present and type 11 has consistently given the unsatistactory formula auto/ $h$ showing autoagglutination in the live state with $h$ revealed after autoclaving. 
These formulae differ from those of Oeding for the international types. It is tentacively suggested that the differences may in part be due to the use of $8 \% \mathrm{NaCl}$ nutrient agar as the medium from which the types were harvested before being used as antigens.

The absorption of an antiserum with its autoclaved homologous strain can, on occasion, enhance the agglutination of the formolinized homologue and antigenically related heterologues.

I am indebted to Professor W. J. Tulloch for facilities and criticism; to Dr. D. M. Green, who, as neutral observer, read the present series of agglutination and precipitation tests; and to my laboratory colleague, Dr. T. Sommerville, and clinical colleagues, Drs. W. Jamieson, Mary R. Kerr, and S. G. F. Wilson, with whom the team-work on field strains was carried out.

\section{REFERENCES}

Brodie, J. (1942). J. Path. Bact., 54, 499.

—_ and Green, D. M. (1951). J. gen. Microbiol., 5, 1001.

_- Jamieson, W., and Sommerville, T. (1955). Lancet, 2, 223. Kerr, M. R., and Sommerville, T. (1956a). Ibid., 1, 19.

- Sommervil!e, T., and Wilson, S. G. F. (1956b). Brit. med. J 1. 667 .

Christie, R., and Keogh, E. V. (1940). J. Path. Bact., 51, 189. Cowan, S. T. (1938). Ibid., 46, 31. - (1939). Ibid., 48, 169.

Fuller, A. T. (1938). Brit. J. exp. Path., 19, 130.

Hobbs, B. C. (1948). J. Hyg. (Camb.), 46, 222.

Hofmeister, F. (1888a). Arch. exp. Path. Pharmak., 24, 247.

- (1888b). Ibid., 25, 1 .

Jurianelle, L. A., and Wieghard, C. W. (1935). J. exp. Med., 62. $11 \frac{0}{0}$ 31.

Koch, F. E. (1942). Zbl. Bakt., 1. Abt. Orig., 149, 122.
Mackie, T. J., and McCartney, J. E. (1953). Handbook of Practical $\overrightarrow{0}$ Bacteriology, 9th ed., p. 330. Livings tone, Edinburgh.

Oeding, P. (1952). Acta path. microbiol. scand., Suppl. 93, p. 356. (1953). Ibid., 33, 312, 324.

(1954). Ibid., 34, 34 . 